\title{
Metabolic Profiles of Clinical Strain of Staphylococcus aureus to Subtle Changes in the Environmental Parameters at Different Phases of Growth
}

\author{
Mousa M. Alreshidi 1 \\ Department of Biology, College of Sciences, University of Ha'il, Hail, Saudi Arabia.
}

\begin{abstract}
Staphylococcus aureus is an important pathogen that can lead to high number of infections worldwide. The present study was aimed to investigate cytoplasmic metabolites of $S$. aureus at mid-exponential and stationary phases following growth in a combination of conditions including variations in $\mathrm{pH}$ and temperature. The result of metabolic analysis demonstrated that most of the metabolites measured at stationary phase under optimal conditions were significantly altered in comparison to equivalent cells harvested at mid- exponential phase. The major alteration was mainly observed in nitrogenous bases and organic acids, which were relatively decreased in cells grown to stationary phase, while mannitol, galactonic acid and adenosine were relatively increased in the cultures harvested at stationary phase. At both phases, the metabolic profiles were substantially different between cultures grown under ideal control conditions compared with those grown under more acidic and alkali conditions with lower temperature of $35^{\circ} \mathrm{C}$. The analyses of cells harvested from control and treatment samples at mid-exponential phase showed that nitrogenous bases including uracil and adenine were significantly decrease in treatment groups compared with reference controls. However, these metabolites were relatively increased in the treatment cells grown to stationary phase. It was evident that variants in environmental parameters led to differential profiles of cytoplasmic metabolites during adaptation processes to applied conditions. These results provided robust evidence supporting the hypothesis that specific alterations in cytoplasmic metabolites were essential for $S$. aureus to adapt and hence survive under changes in the environmental parameters.
\end{abstract}

Keywords: Cytoplasmic metabolites, S. aureus, metabolic homeostasis, stress responses

\footnotetext{
*Correspondence: mousa.algladi@gmail.com

(Received: February 02, 2020; accepted: March 06, 2020)

Citation: Mousa M. Alreshidi, Metabolic Profiles of Clinical Strain of Staphylococcus aureus to Subtle Changes in the Environmental Parameters at Different Phases of Growth, J. Pure Appl. Microbiol., 2020; 14(1):415-422. https://doi.org/10.22207/JPAM.14.1.43

(C) The Author(s) 2020. Open Access. This article is distributed under the terms of the Creative Commons Attribution 4.0 International License which permits unrestricted use, sharing, distribution, and reproduction in any medium, provided you give appropriate credit to the original author(s) and the source, provide a link to the Creative Commons license, and indicate if changes were made.
} 


\section{INTRODUCTION}

Infections due to staphylococcus aureus have been increased at a remarkable rate in the past era worldwide. The extraordinary feature of this bacterium is its ability to adapt to a wide range of environmental conditions ${ }^{1-3}$. However, the processes involved in the adaptations of $S$. aureus in response to combination of environmental stresses are still not clear. It has been suggested that alterations in the profiles of cellular compositions are vital for bacterial adaptation and infection occurrence ${ }^{4-6}$. It has been reported that staphylococcal adaptation mechanism in response to limited nutrients occurred through a significant changes in the patterns of enzymes and metabolites ${ }^{7}$. When $S$. aureus was grown under sub-optimal conditions, significant changes in the cytoplasmic amino acid, fatty acid and protein patterns were observed ${ }^{6,8}$. Thus, it was assumed that characteristic and specific changes in the amino acid and fatty acid metabolites as well as protein composition led to the survival of S. aureus when exposed to confined nutrition in combination with higher concentrations of $\mathrm{NaCl}^{9}$. A recent study indicated that hydrogen peroxide $\left(\mathrm{H}_{2} \mathrm{O}_{2}\right)$ combined with various temperatures and $\mathrm{pH}$ induced alterations in the amino acid profiles of clinical isolate of $S$. aureus ${ }^{10}$.

S. aureus, have been shown to adapt, survive and even proliferate under these adverse conditions encountered in wound site, leading to a serious infections ${ }^{11}$. One adaptive response in S. aureus towards conditions present on human skin or within a wound site is the alterations in metabolites and proteins toward obtain the optimum homeostasis ${ }^{12,13}$. A lower temperature of $35^{\circ} \mathrm{C}$ combined with either lower or higher $\mathrm{pH}$ induced significant changes in the amino acid levels and protein compositions ${ }^{6}$. However, till now the same experimental design has not been adapted to investigate nucleotides, nucleosides, organic acids and sugar alcohol abundances in response to the conditions of more acidic and alkali combined with lower temperature of $35^{\circ} \mathrm{C}$. Thus, this study was aimed to determine the metabolic alterations that could occur as a result of alterations in $\mathrm{pH}$ and temperature. It was hypothesized that the exposure of $S$. aureus to conditions of more acidic and alkali with lower temperature would lead to remarkable changes in the metabolic profiles.

\section{MATERIAL AND METHODS}

\section{S. aureus strain and Growth conditions}

S. aureus used in the current study was isolated from patients who were suffering from chronic muscle pain ${ }^{14}$. This bacterium was used in following investigations to study metabolic and proteomic adaptation to alterations in the environmental factors ${ }^{5,6,9}$.

Staphylococcus aureus was cultured in a sub-optimal of environmental parameters including alteration in $\mathrm{pH}$ and temperature for analyses of cytoplasm metabolites following growth in tryptic soy broth media (TSB) (Oxoid Ltd-Australia). The control included cells grown under ideal conditions of $\mathrm{pH} 7$ at $37^{\circ} \mathrm{C}$ in tryptic soy broth medium (TSB) and two sets of experimental conditions were applied with (1) $35^{\circ} \mathrm{C}$ and $\mathrm{pH} 6$ with and (2) $35^{\circ} \mathrm{C}$ and $\mathrm{pH} 8$.

\section{Metabolites extraction}

Washed cells were lysed using snapfrozen and thawing technique 3 times and placed in a dryer machine overnight. Approximately 10-12 mg of lyophilized cells were resuspended with $10 \mathrm{ml}$ of $1: 1(\mathrm{v} / \mathrm{v})$ of cold methanol/water stored at $-20^{\circ} \mathrm{C}$ and mixed thoroughly. The methanol/water lyophilized cell slurries were snap frozen in liquid nitrogen and placed in freezer at $\left(-20^{\circ} \mathrm{C}\right)$ for $30 \mathrm{~min}$ for a process of slow thawing. Metabolites were then separated from the cell debris by centrifugation at $6,500 \mathrm{xg}$ for $25 \mathrm{~min}$. The supernatants containing the metabolites were dried using a centrifugal vacuum drier (CentriVap, LABCORNCO, VWR) .

\section{Metabolites identification and quantification}

Dried cytoplasmic metabolites including carbohydrates and purine and pyrimidine metabolites were evaluated by forming the methoxy-amine-trimethylsilyl (TMS) derivativesby reacting the dry extracts with Methoxyamine- $\mathrm{HCL}$ (MOX) and Bis(trimethylsily) trifluoraacetamide (BSTFA). Lyophilised metabolites were mixed with $50 \mu \mathrm{l}$ of MOX vortexed very well, and then heated at $60^{\circ} \mathrm{C}$ for $30 \mathrm{~min}$. Samples were then allowed to cool and subsequently $150 \mu$ l of BSTFA was added to each sample, vortexed and heated at $100^{\circ} \mathrm{C}$ for $60 \mathrm{~min}$. Derivatised samples were analysed by auto-sampler gas chromatography (Agilent, Hewlett-Packed 5973) coupled with mass spectrometry. The injection volume was $1 \mu \mathrm{l} /$ sample and flow rate was $0.5 \mathrm{ml} / \mathrm{min}$. Metabolites 
in the chromatogram were identified on the basis of matching their mass spectra and retention time indices with data in use-generated mass spectral libraries generated from reference standards.

GC-MS data processing and statistical analysis

The acquired metabolite data obtained from GC-MS were exported to an Excel $^{\circledR}$ (Microsoft $^{\circledR}$ ) sheet. The exported data were then imported to STATISTICA (6, StatSoft) (ANOVA) to find the cytoplasmic metabolites that were considerably different between control and treatment groups. Multivariate analysis including principal component analysis (PCA) was then preformed utilizing STATISTICA (6, StatSoft) to further the analysis and have a better understanding.

\section{RESULTS}

Metabolites analysis of cells grown under normal conditions harvested at mid-exponential and stationary phases

Cultures of $S$. aureus were grown in TSB to mid-exponential and stationary phases of growth under optimal conditions $\left(\mathrm{pH} 7,37^{\circ} \mathrm{C}\right.$ and no added $\mathrm{NaCl}$ ). The analyses of the cytoplasmic metabolites revealed the presence of 13 metabolites that could be identified by the GC-MS method based on their retention time indices and mass spectra as shown in Fig. 1. The cytoplasmic metabolite profiles were assessed as percentage abundances from stationary phase for comparison with midexponential phase. The analysis indicated that significant changes in the relative abundances of many metabolites of cells grown to the stationary phase compared with those analysed at midexponential phase. For instance, lactic acid and galactonic acid were relatively increased in cells harvested at stationary phases compared with mid-exponential phase cells, but the succinic acid was substantially decreased when bacterial cells grown to stationary phase. Purine bases including guanine and adenine were relatively reduced in cells grown to stationary phase in comparison to mid-exponential phases. On other hand, adenosine was relatively increased, but guanosine was significantly decreased.

The cytoplasmic metabolites were further investigated through multivariate analysis using PCA. The result revealed that the metabolites analysed from both phases were very well clustered and reproducible with each phase. However, the analysis clearly showed that metabolic profiles of cells harvested at midexponential phase was well separated from those collected at stationary phase, indicating that a significant difference between the two phases. Mid-exponential phase metabolites were clustered at the negative side of component 1 whereas stationary phase metabolites were spread along positive side.

\section{Metabolites analysis at mid-exponential phase}

Metabolite responses from cells collected at mid-exponential phase following exposure to changes in $\mathrm{pH}$ and temperature were determined using GC-MS (Fig. 3). The results indicated that nitrogenous bases including adenine, guanine,

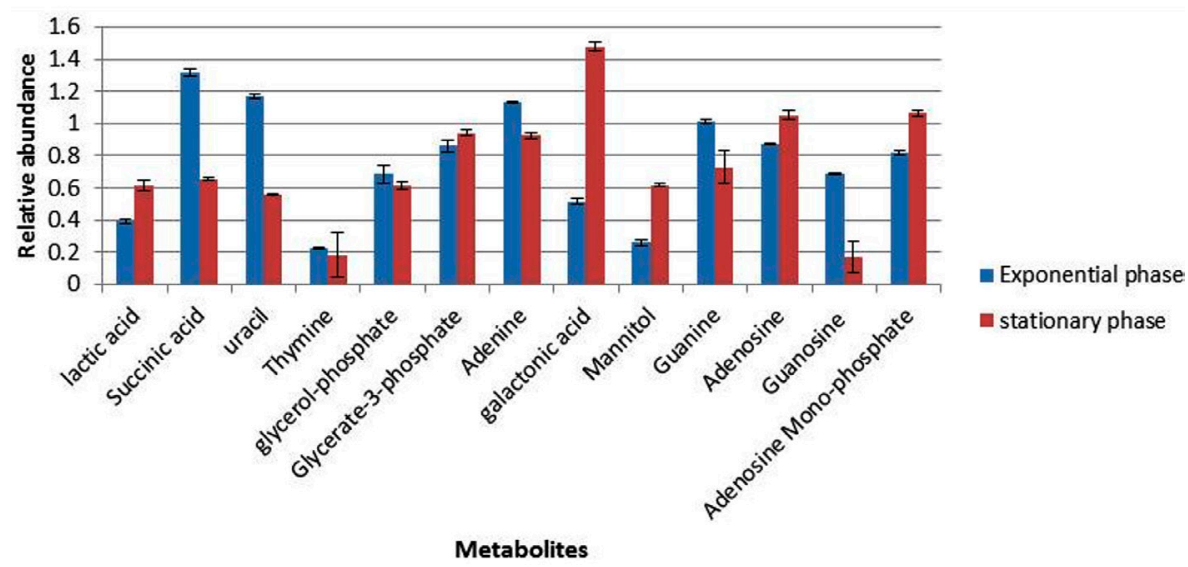

Fig. 1. The relative abundances of cytoplasmic metabolites extracted from clinical isolate of $S$. aureus harvested at mid-exponential and stationary phases grown under ideal conditions 
thymine and uracil were relatively decrease in the cultures grown with either more acidic or alkali conditions, with exception of thymine that did not display a change in response to more alkali conditions with lower temperature of $35^{\circ} \mathrm{C}$. Lactic acid and mannitol were relatively increased in cells grown in altered conditions compared to cells grown in normal conditions. Adenosine and guanosine were substantially decreased in cells grown under more acidic conditions ( $\mathrm{pH} 6)$, but were significantly increased in the cells grown with more alkali conditions in comparison to reference control.

Detected metabolites were subjected to multivariate analysis such as PCA to further investigate the dimensionality of these metabolites following exposure to changes in $\mathrm{pH}$ and temperature. The PCA analysis demonstrated that each treatment regimen resulted in a significant metabolic profile, with great reproducibility within each group. As depicted by PCA plot the treatment groups were very well separated from the control samples. The cells grown under normal conditions (A1-A4) positioned in the negative side of PCA plot while the cells exposed to lower $\mathrm{pH}$ of 6 (B1-B4) or higher $\mathrm{pH}$ of 8 (C1-C4) with lower temperature placed in the positive side of the plot.

\section{Metabolites analysis at stationary phase}

The cells were grown further to the stationary phase under the same conditions designated as ( $A$ to $C$ ) before extraction of cytoplasmic metabolites and the analysis by GC-MS. The results indicated that lactic acid, galactonic acid and succinic acid were relatively decreased in cells grown in altered environmental parameters with exception of galactonic acid which did not exhibit any change in response to more alkali condition (Fig. 5). The nitrogenous bases include uracil and adenine were remarkably increased in both treatment regimens ( $B$ and $C$ ) compared with control samples (A), but thymine and guanine remained consistent in cells exposed to lower $\mathrm{pH}$ and higher $\mathrm{pH}$. Both adenosine and guanosine were greatly decreased in cells grown under more acidic $(\mathrm{pH} 6)$ and alkali $(\mathrm{pH} 8)$ conditions. Adversely, adenosine mono-phosphate was significantly increased in response to altered environmental conditions.

The metabolite profiles were further analysed using principal component analysis (PCA). The plot of PCA revealed that the metabolite profiles were again very distinct from each other as shown for metabolites analysed at midexponential phase. The results also displayed that

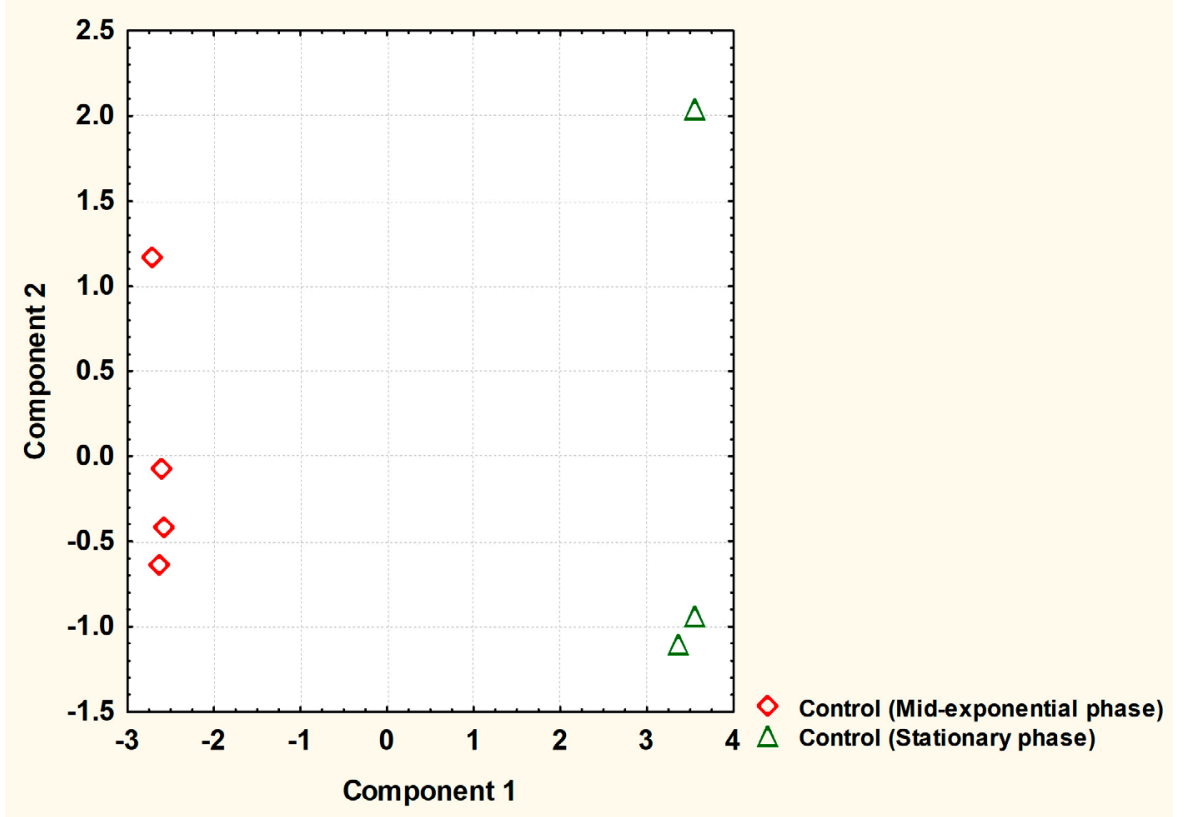

Fig. 2. The principal component analysis (PCA) of S. aureus cytoplasmic metabolite profiles derived from cells grown to mid-exponential and stationary phases under normal conditions. 


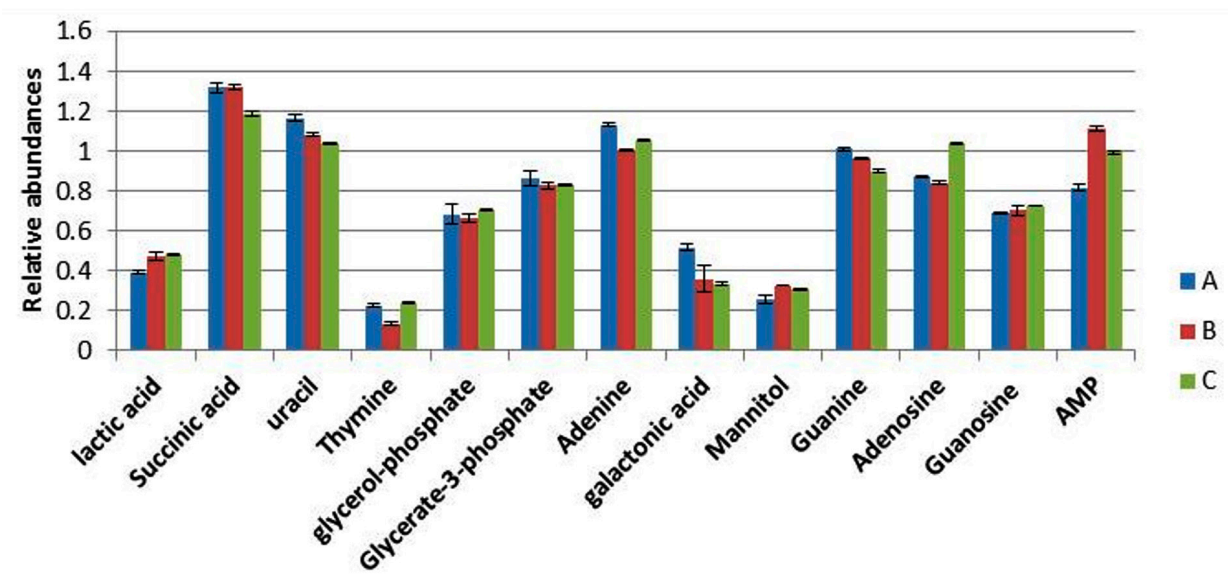

Metabolites

Fig. 3. The relative abundances of cytoplasmic metabolites extracted from clinical isolate of $S$. aureus harvested at mid-exponential from cells grown under normal conditions $(\mathrm{A})$, , $\mathrm{pH} 6,35^{\circ} \mathrm{C}(\mathrm{B})$ and $\mathrm{pH} 8$ at $35^{\circ} \mathrm{C}(\mathrm{C})$.

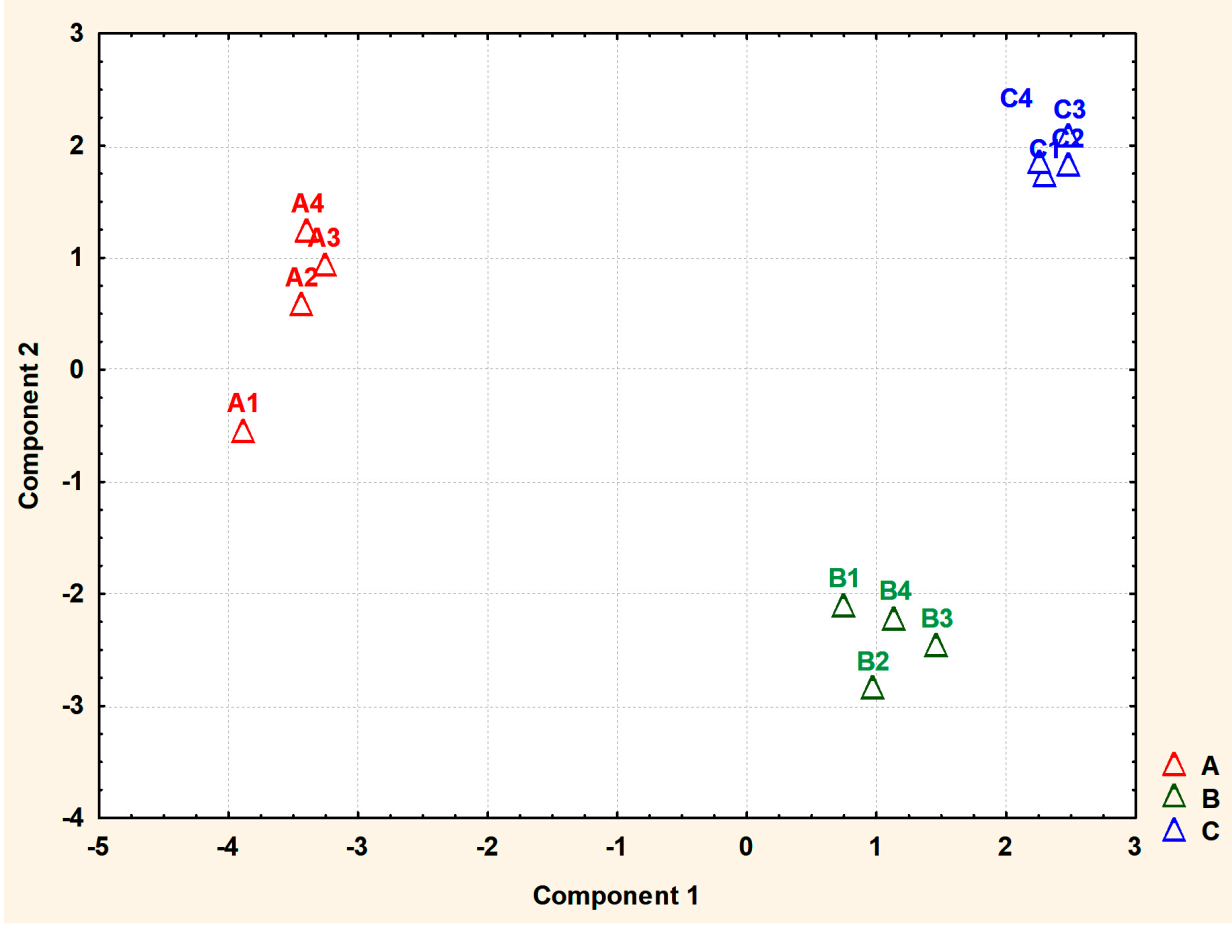

Fig. 4. Principal component analysis (PCA) scores (component1 versus component 2) plotted from cytoplasmic metabolite data of $\mathrm{S}$. aureus. The $\mathrm{S}$. aureus cultures were grown under (A1-A4) ideal conditions at $\mathrm{pH} 7{ }_{-} 37^{\circ} \mathrm{C}$ (control), $\mathrm{pH} 6$ at $35^{\circ} \mathrm{C},(\mathrm{B} 1-\mathrm{B} 4)$ and $\mathrm{pH} 8$ at $35^{\circ} \mathrm{C}(\mathrm{C} 1-\mathrm{C} 4)$ to mid-exponential phase of growth before extraction of cytoplasmic metabolites and analysis by GC-MS.

control and treatment samples were very well separated. Control replicates were resolved along the negative axis, while the cells exposed to more acidic and alkali conditions were spread along the positive axis. These analyses showed that the metabolite profiles were distinct between each of treatments and control. 


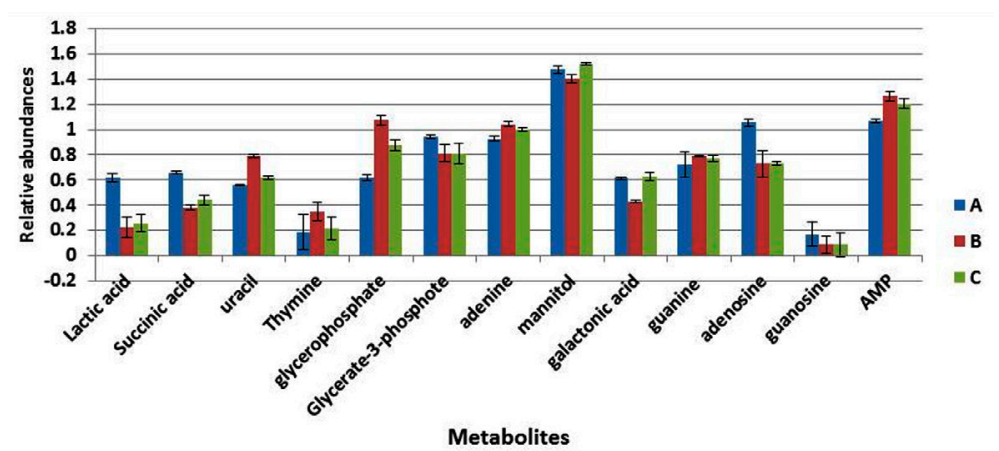

Fig. 5. The relative abundances of cytoplasmic metabolites extracted from clinical isolate of $S$. aureus harvested at stationary phase from cells grown under normal conditions (A), $\mathrm{pH} 6,35^{\circ} \mathrm{C}(\mathrm{B})$ and $\mathrm{pH} 8$ at $35^{\circ} \mathrm{C}(\mathrm{C})$.

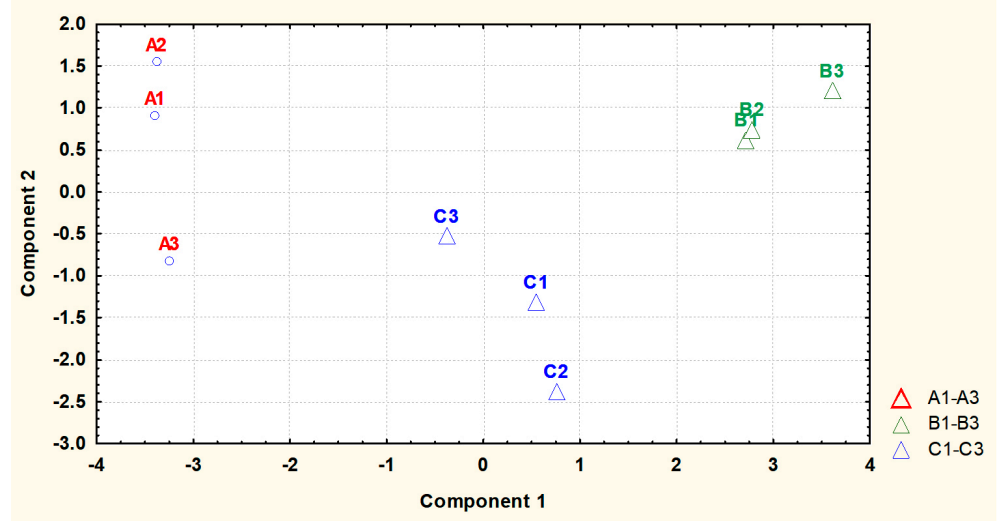

Fig. 6. Principal component analysis (PCA) scores (component1 versus component 2) plotted from cytoplasmic metabolite data of $S$. aureus harvested at stationary phase. The $S$. aureus cultures were grown under (A1-A4) ideal conditions at $\mathrm{pH} 737^{\circ} \mathrm{C}$ (control), (B1-B4) $\mathrm{pH} 6$ at $35^{\circ} \mathrm{C}$, and $(\mathrm{C} 1-\mathrm{C} 4) \mathrm{pH} 8$ at $35^{\circ} \mathrm{C}$ to stationary phase of growth before extraction of cytoplasmic metabolites and analysis by GC-MS.

\section{DISCUSSION}

The results from this investigation indicated that the cytoplasmic composition of selected metabolites of control cultures of $S$. aureus grown to mid-exponential phase had a different metabolites composition compared with cultures harvested at the stationary phase. These substantial alterations in the metabolites in the stationary phase could be a mechanism to combat the complex environments present in the stationary phase including the exhaustion of nutrients and accumulation of toxic waste from metabolic products ${ }^{15,16}$. Cells entered the stationary phase had a lower nitrogenous bases relative to active cells at mid-exponential phase. Previous studies have shown that lactic acid bacteria reduced the production of DNA and proteins during the growth in the stationary phase ${ }^{17,18}$. The increase observed in organic acids such as lactic and galactonic acids in the cells grown to the stationary phase possibly due to the catabolism of the carbohydrate in the cells. The reduction in cytoplasmic metabolites in the cells grown to stationary phase could be attributed to reduced metabolic rates to preserve energy during undesirable conditions ${ }^{19-21}$. The great increase in the mannitol level in the stationary phase cultures could be due to the requirement of this molecule to help the bacteria to cope with stationary phase conditions. It has been shown that mannitol was important to enhance the survivability of $S$. aureus against antimicrobial fatty acids present on human skin $^{22}$.

Metabolic analysis of cells harvested at mid-exponential phase after being exposed to changes in $\mathrm{pH}$ and temperature, revealed different metabolic profiles. For example, a significant alteration in the nitrogenous bases was observed, this possibly a mechanism to encounter the stressful condition present in the 
growth conditions. Metabolic studies displayed a significant increase in the concentrations of many cytoplasmic metabolites in Salmonella in response to altered environmental conditions s $^{23,24}$. Earlier studies have shown that $S$. aureus altered many genes in order to combat changes in $\mathrm{pH}$ and hence facilitate survival ${ }^{25-28}$. An identical study showed that amino acid and protein composition of $S$. aureus were remarkably altered following exposure to either $\mathrm{pH} 6$ or $\mathrm{pH} 8$ combined with lower temperature of $35^{\circ} \mathrm{C}^{6,29}$. Another study determined significant changes in the fatty acid composition and cell sizes of Staphylococcus lugdunensis in response to alterations in environmental conditions including changes in $\mathrm{pH}$ and temperature ${ }^{8}$. A recent study exhibited that hydrogen peroxide combined with other environmental factors such as altered $\mathrm{pH}$ and temperature led to very different metabolic profiles of a clinical isolate of $S$. aureus ${ }^{10}$, suggested these alterations in amino acids were essential for survival under changes in the environmental conditions. Moreover, a new study revealed that $S$. aureus taken up and released different levels of amino acids following growth in altered environmental conditions ${ }^{29}$.

Cells harvested at stationary phase produced significant alterations in their metabolite abundances in comparison to reference controls. This probably a strategy used by bacteria to cope with stressful condition, once this stress removed cells will restart replicate. An earlier study showed that extreme cold stress led to a significant reduction in the amino acid metabolites ${ }^{5}$. The higher abundances of purine and pyrimidine bases in cells grown in altered environmental conditions could be associated with protein synthesis. It has been shown that Escherichia coli produced high quantity of proteins at stationary phase ${ }^{30}$. The synthesis of proteins in high concentrations could be a mechanism to enhance the adaptation and hence the survivability of $S$. aureus at complex environment present in stationary phase. $S$. aureus was shown to consumed different levels of amino acids in response to various environmental conditions at stationary phase ${ }^{29}$, suggesting that different amino acid uptakes were required for adaptation under various temperature and $\mathrm{pH}$.

\section{CONCLUSION}

Staphylococcus aureus remains one of the challenge pathogens in hospital due to its remarkable ability to adapt to wide range of environmental conditions. This study determined that different growth phases of $S$. aureus led to significant adjustments in metabolic homeostasis under normal conditions. In additions, the exposure of $S$. aureus to more acidic or alkali conditions with lower temperature of $35{ }^{\circ} \mathrm{C}$ resulted to specific metabolic profiles associated with each treatment regimen. The outcome of this study was interpreted to show that alterations in metabolic homeostasis were required to the different growth conditions. The differential responses elicited by the bacterium under each treatment led to characteristic metabolic profiles for adaptation to achieve a homeostasis for survival.

\section{ACKNOWLEDGMENTS}

This work was supported by the University of Ha'll (grant No. 160984). I would like to express my appreciation to Prof. Hugh Dunstan and Prof. Tim Roberts for their assistance and support.

\section{FUNDING}

This work was supported by the University of Ha'll (grant No. 160984).

\section{DATA AVAILABILITY}

All datasets generated or analyzed during this study are included in the manuscript.

\section{ETHICS STATEMENT}

Not applicable.

\section{REFERENCES}

1. Onyango LA and MM Alreshidi. Adaptive Metabolism in Staphylococci: Survival and Persistence in Environmental and Clinical Settings. J Pathog, 2018; 2018: 1092632. https://doi.org/10.1155/2018/1092632

2. Jongerius I et al. Staphylococcus aureus Virulence Is Enhanced by Secreted Factors That Block Innate Immune Defenses. Innate Immunity, 2012; 4: 301-311. https://doi.org/10.1159/000334604

3. Haste NM et al. Activity of the thiopeptide antibiotic nosiheptide against contemporary strains of methicillin-resistant S. aureus. J Antibiot (Tokyo), 2012; 65(12): 593-8. https://doi.org/10.1038/ja.2012.77

4. Farrand AJ et al. Proteomic analyses of iron-responsive, Clp-dependent changes in S. aureus. Pathog Dis, 2015; 73(3). https://doi.org/10.1093/femspd/ftv004 
5. Alreshidi MM et al. Metabolomic and proteomic responses of Staphylococcus aureus to prolonged cold stress. J Proteomics, 2015; 121: 44-55. https:// doi.org/10.1016/j.jprot.2015.03.010

6. Alreshidi MM et al. Changes in the Cytoplasmic Composition of Amino Acids and Proteins Observed in Staphylococcus aureus during Growth under Variable Growth Conditions Representative of the Human Wound Site. PLoS One, 2016; 11(7): e0159662. https:// doi.org/10.1371/journal.pone.0159662

7. Liebeke $\mathrm{M}$ et al. A metabolomics and proteomics study of the adaptation of Staphylococcus aureus to glucose starvation. Molecular Biosystems, 2011; 7(4): 1241-1253. https://doi.org/10.1039/c0mb00315h

8. Crompton MJ et al. Small changes in environmental parameters lead to alterations in antibiotic resistance, cell morphology and membrane fatty acid composition in S. lugdunensis. PLoS One, 2014; 9(4): e92296. https://doi.org/10.1371/journal.pone.0092296

9. Alreshidi MM et al. Amino acids and proteomic acclimation of Staphylococcus aureus when incubated in a defined minimal medium supplemented with $5 \%$ sodium chloride. Microbiologyopen, 2019; 8(6): e00772. https://doi.org/10.1002/mbo3.772

10. Murphy GR et al. Alterations in amino acid metabolism during growth by Staphylococcus aureus following exposure to $\mathrm{H} 2 \mathrm{O} 2$ - A multifactorial approach. Heliyon, 2018; 4(5): p. e00620. https://doi.org/10.1016/j. heliyon.2018.e00620

11. Carrera M et al. Characterization of Foodborne Strains of Staphylococcus aureus by Shotgun Proteomics: Functional Networks, Virulence Factors and SpeciesSpecific Peptide Biomarkers. Front Microbiol, 2017. 8: 2458. https://doi.org/10.1016/j.heliyon.2018.e00620

12. Sianglum $\mathrm{W}$ et al. Proteome analyses of cellular proteins in methicillin-resistant S.aureus treated with rhodomyrtone, a novel antibiotic candidate. PloS one, 2011; 6(2): e16628. https://doi.org/10.1371/journal. pone.0016628

13. Mack D et al. Mechanisms of biofilm formation in Staphylococcus epidermidis and Staphylococcus aureus: functional molecules, regulatory circuits, and adaptive responses. International journal of medical microbiology : IJMM, 2004; 294(2-3): 203-12. https:// doi.org/10.1016/j.ijmm.2004.06.015

14. Butt HL et al. An association of membrane-damaging toxins from coagulase-negative staphylococci and chronic orofacial muscle pain. Journal of Medical Microbiology, 1998; 47(7): 577-84. https://doi. org/10.1099/00222615-47-7-577

15. Ou J et al. Stationary phase protein overproduction is a fundamental capability of Escherichia coli. Biochem Biophys Res Commun, 2004; 314(1): 174-80. https:// doi.org/10.1016/j.bbrc.2003.12.077

16. Nystrom T. Stationary-phase physiology. Annu Rev Microbiol, 2004. 58: 161-81. https://doi.org/10.1146/ annurev.micro.58.030603.123818

17. Ganesan B, MR Stuart and BC Weimer. Carbohydrate starvation causes a metabolically active but nonculturable state in Lactococcus lactis. Appl Environ Microbiol, 2007; 73(8): 2498-512. https://doi.

\section{org/10.1128/AEM.01832-06}

18. Papadimitriou K et al. Stress Physiology of Lactic Acid Bacteria. Microbiol Mol Biol Rev, 2016; 80(3): 837-90. https://doi.org/10.1128/MMBR.00076-15

19. Vuong C et al. Staphylococcus epidermidis polysaccharide intercellular adhesin production significantly increases during tricarboxylic acid cycle stress. J Bacteriol, 2005; 187(9): 2967-73. https://doi. org/10.1128/JB.187.9.2967-2973.2005

20. Spentzas T et al. Role of bacterial components in macrophage activation by the LAC and MW2 strains of community-associated, methicillin-resistant Staphylococcus aureus. Cell Immunol, 2011; 269(1): 46-53. https://doi.org/10.1016/j.cellimm.2011.03.009

21. Silva LV et al. Evaluation of the synergistic potential of vancomycin combined with other antimicrobial agents against methicillin-resistant Staphylococcus aureus and coagulase-negative Staphylococcus spp strains. Mem Inst Oswaldo Cruz, 2011; 106(1): 44-50. https://doi. org/10.1590/S0074-02762011000100007

22. Kenny JG et al. Mannitol utilisation is required for protection of Staphylococcus aureus from human skin antimicrobial fatty acids. PLoS One, 2013; 8(7): e67698. https://doi.org/10.1371/journal.pone.0067698

23. Stipetic LH et al. A novel metabolomic approach used for the comparison of $S$. aureus planktonic cells and biofilm samples. Metabolomics, 2016; 12:. 75. https:// doi.org/10.1007/s11306-016-1002-0

24. Burgess CM et al. The response of foodborne pathogens to osmotic and desiccation stresses in the food chain. Int J Food Microbiol, 2016; 221: 37-53. https://doi.org/10.1016/j.ijfoodmicro.2015.12.014

25. Anderson $\mathrm{KL}$ et al. Characterizing the effects of inorganic acid and alkaline shock on the Staphylococcus aureus transcriptome and messenger RNA turnover. FEMS Immunol Med Microbiol, 2010; 60(3): 208-50. https://doi.org/10.1111/j.1574-695X.2010.00736.x

26. Ricciardolo FL. Mechanisms of citric acid-induced bronchoconstriction. Am J Med, 2001; 111 Suppl 8A: 18S-24S. https://doi.org/10.1016/S00029343(01)00816-6

27. Lemaire $\mathrm{S}$ et al. Role of acidic $\mathrm{pH}$ in the susceptibility of intraphagocytic methicillin-resistant Staphylococcus aureus strains to meropenem and cloxacillin. Antimicrob Agents Chemother, 2007; 51(5): 1627-32. https://doi.org/10.1128/AAC.01192-06

28. Jones EM, CA Cochrane and SL Percival. The Effect of $\mathrm{pH}$ on the Extracellular Matrix and Biofilms. Adv Wound Care (New Rochelle), 2015; 4(7): 431-439. https://doi. org/10.1089/wound.2014.0538

29. Alreshidi MM et al. The Uptake and Release of Amino Acids by Staphylococcus aureus at Mid-Exponential and Stationary Phases and Their Corresponding Responses to Changes in Temperature, $\mathrm{pH}$ and Osmolality. Front. Microbiol., 2020; 10: 3059. https:// doi.org/10.3389/fmicb.2019.03059

30. Gefen $\mathrm{O}$ et al. Direct observation of single stationaryphase bacteria reveals a surprisingly long period of constant protein production activity. Proc Natl Acad Sci US A, 2014; 111(1): 556-61. https://doi.org/10.1073/ pnas. 1314114111 